\title{
CONSÓRCIO ENTRE FEIJÃo E Brachiaria brizantha SOB DOSES REDUZIDAS DE GRAMINICIDA ${ }^{1}$
}

\author{
Bean Intercropped with Brachiaria brizantha Under Reduced Graminicide Doses
}

\author{
SILVA, A.C. ${ }^{2}$, CARNEIRO, J.E.S. ${ }^{3}$, FERREIRA, L.R. ${ }^{3}$ e CECON, P.R. ${ }^{4}$
}

\begin{abstract}
RESUMO - Objetivou-se neste trabalho avaliar a viabilidade do consórcio entre os cultivares de feijão BRS Valente e Diamante Negro com Brachiaria brizantha cv. MG5, submetidos a doses reduzidas de fluazifop-p-butil. Utilizou-se um esquema de parcelas subdivididas, tendo na parcela principal dois cultivares de feijão (Diamante Negro e BRS Valente) consorciados com $B$. brizantha e na subparcela as doses de fluazifop-p-butil $\left(0,15,30,45\right.$, 60 e $\left.75 \mathrm{~g} \mathrm{ha}^{-1}\right)$, no delineamento em blocos casualizados com quatro repetições. B. brizantha e os cultivares de feijão foram avaliados também em monocultivo, utilizando capina manual. Foram determinados o estande final, a produtividade de grãos, o peso de 100 sementes, o número de vagens por planta e de sementes por vagem dos cultivares de feijão. B. brizantha foi coletada aos 25 dias após a colheita do cultivar BRS Valente, avaliando-se a biomassa seca da parte aérea e a altura do dossel. Os cultivares de feijão BRS Valente e Diamante Negro semeados na safra das águas não foram afetados pelo consórcio com B. brizantha; o cultivar BRS Valente $\left(1,80 t^{h a^{-1}}\right)$ mostrou-se mais adequado a essa época de plantio em relação ao Diamante Negro $\left(1,31 \mathrm{t} \mathrm{ha}^{-1}\right)$. O feijoeiro foi altamente competitivo com B. brizantha, ocasionando redução no acúmulo de biomassa seca da forrageira de $50 \%$ em relação a $B$. brizantha em monocultivo. Comparada ao consórcio sem aplicação de herbicida, a dose de $15 \mathrm{~g} \mathrm{ha}^{-1}$ do fluazifop-p-butil reduziu em 12 e $13 \%$ a biomassa seca e a altura do dossel da forrageira, respectivamente. A partir de $21 \mathrm{~g} \mathrm{ha}^{-1}$ de fluazifop-p-butil a forrageira mostrou-se altamente sensivel ao herbicida, apresentando acúmulo de biomassa extremamente reduzido.
\end{abstract}

Palavras-chave: Phaseolus vulgaris, braquiária, herbicida, integração agricultura-pecuária, plantio direto.

\begin{abstract}
The objective of this work was to evaluate Brachiaria brizantha intercropped with BRS Valente and Diamante Negro bean cultivars under reduced rates of fluazifop-p-butyl. The experiment was conducted in a randomized complete block arrangement, with four replications, in a split-plot design. The bean cultivars intercropped with $\boldsymbol{B}$. brizantha constituted the plot (Diamante Negro and BRS Valente) and the doses of fluazifop-p-butyl the split-plots. B. brizantha and the bean cultivars were evaluated in monocrop kept clean by hand hoeing. Final stand, grain yield, 100-seed weight, number of pods per plant and number of seeds per pod of bean cultivars were evaluated. B. brizantha was collected 25 days after BRS Valente cultivar harvest, evaluating aerial dry biomass of the aerial part and canopy height. BRS Valente and Diamante Negro, were not affected by B. brizantha intercrop; it was observed that BRS Valente cultivar (1.80 tha $\left.\mathrm{a}^{-1}\right)$ was more adequate for this planting timing, in relation to Diamante Negro cultivar (1.31 t ha $\mathrm{h}^{-1}$ ). Bean plants were very competitive with B. brizantha reducing forage dry biomass of $50 \%$ relative to $\boldsymbol{B}$. brizantha monocrop. Intercrop without herbicide compared to $15 \mathrm{~g} \mathrm{ha}^{-1}$ of fluazifop-p-butyl showed that the treatment with herbicide reduced in 12 and 13\% the dry biomass and canopy height, respectively. Above $21 \mathrm{~g} \mathrm{ha}^{-1}$ of fluazifop-pbutyl, the forage showed highly susceptible to the herbicide, presenting an extremely reduced biomass accumulation.
\end{abstract}

Keywords: Phaseolus vulgaris, Brachiaria, herbicide, crop-livestock integration, no-till.

Recebido para publicação em 10.12.2004 e na forma revisada em 24.2.2006.

2 Pesquisadora da Agência Paulista de Tecnologia dos Agronegócios - APTA, Pólo Regional da Alta Sorocabana, 19015-970 Presidente Prudente-SP, Caixa Postal 298, <andreiacs@ aptaregional.sp.gov.br>; ${ }^{3}$ Prof. Adjunto do Dep. de Fitotecnia da Universidade Federal de Viçosa - UFV; ${ }^{4}$ Prof. Adjunto do Dep. de Informática da UFV. 


\section{INTRODUÇÃO}

Vários trabalhos demonstram maior produtividade do feijoeiro no sistema de plantio direto em relação ao sistema de plantio convencional (Galvão et al., 1981; Stone \& Silveira, 1999; Silva, 2001), observando-se incremento na produção de biomassa seca total, no índice de área foliar, na taxa de crescimento da cultura, na taxa de crescimento relativo, na taxa assimilatória líquida e na duração da área foliar (Urchei et al., 2000).

Todavia, apesar dos benefícios proporcionados, o sistema de plantio direto depende de fontes eficientes de cobertura morta, capazes de proteger plenamente a superfície do solo e ter longevidade adequada. Nesse sentido, a palhada das espécies do gênero Brachiaria tem atendido a esses dois quesitos, produzindo mais de $15 \mathrm{t} \mathrm{ha}^{-1}$ de biomassa seca quando corretamente manejada e persistindo por mais de seis meses na superfície do solo (Cobucci, 2001). A palhada de Brachiaria tem exercido também importante papel na redução da incidência de doenças. Costa \& Silveira (1997) relatam que propágulos de Fusarium solani foram reduzidos após $B$. brizantha na cultura do feijão e que a incidência de Rhizoctonia solani foi menor em áreas onde se cultivava o feijoeiro após $B$. ruziziensis, $B$. brizantha e soja.

A espécie produtora de palha exerce grande influência no rendimento de grãos do feijão (Oliveira et al., 2002). A cobertura do solo com capins do gênero Brachiaria pode ser utilizada com êxito para o plantio direto de feijão; maiores quantidades dessas coberturas podem aumentar a produção de sementes (Lolatto et al., 2002). Considerando que a cultura do feijão apresenta baixa relação $\mathrm{C} / \mathrm{N}$, é de fundamental importância a introdução de espécies em rotação ou consorciação que proporcionem cobertura do solo para a viabilização do plantio direto.

A cultura do feijão tem sido amplamente estudada em sistemas consorciados, principalmente com a cultura do milho (Carvalho \& Leal, 1991; Vieira \& Vieira, 1996; Pereira Filho et al., 2000), sendo ela a cultura preferida nesse sistema devido ao ciclo vegetativo curto, por ser pouco competitiva, podendo ser semeada em diferentes épocas, sendo ainda relativamente tolerante com a competição movida pela planta consorciada (Vieira, 1998). Por meio do consórcio de leguminosas e gramíneas com elevada produção de matéria seca, podem-se conciliar proteção e adubação do solo no sistema de plantio direto (Oliveira et al., 2002).

A escolha dos cultivares de feijão utilizados em sistemas consorciados é outro aspecto importante a ser considerado, uma vez que diferentes cultivares apresentam características distintas (porte, velocidade de crescimento inicial, ciclo, entre outras), as quais podem alterar o balanço competitivo. Vieira \& Ramos (1992) e Candal Neto \& Vieira (1994) observaram comportamento diferenciado de cultivares de feijão consorciados com milho.

Objetivou-se neste trabalho avaliar a viabilidade do consórcio entre os cultivares de feijão BRS Valente e Diamante Negro com Brachiaria brizantha cv. MG5, submetidos a doses reduzidas de fluazifop-p-butil, bem como seus efeitos na produtividade de grãos de feijão e no acúmulo de biomassa seca de Brachiaria.

\section{MATERIAL E MÉTODOS}

O experimento foi instalado no campo experimental do Departamento de Fitotecnia UFV, no ano agrícola 2003/2004, em ViçosaMG, em solo classificado como Argissolo Vermelho-Amarelo Câmbico, textura argilosa, cujas principais características químicas são: $\mathrm{pH}$ em água de 6,$7 ; 4,12$ dag $\mathrm{kg}^{-1}$ de matéria orgânica; V de 79\%; teores de P e K de 243,7 e $260,0 \mathrm{mg} \mathrm{dm}^{-3}$ e de $\mathrm{Ca}, \mathrm{Mg}, \mathrm{H}+\mathrm{Al}$ de 5,9, 1,0 e $1,98 \mathrm{de}^{\mathrm{cmol}} \mathrm{dm}^{-3}$, respectivamente. A temperatura máxima e mínima, a umidade relativa e a precipitação pluvial referentes ao período de condução do ensaio são apresentadas na Figura 1.

O experimento foi realizado em sistema de plantio direto, após a dessecação química da cobertura vegetal composta por plantas daninhas. A semeadura de feijão (cultivares Diamante Negro e BRS Valente) e de $B$. brizantha (cv. MG5) foi realizada simultaneamente em 3/12/2003, utilizando-se semeadora específica para plantio direto. O espaçamento utilizado foi de $0,60 \mathrm{~m}$ entre as linhas de feijão, obtendo-se estande aproximado de 265.000 plantas ha ${ }^{-1}$. B. brizantha 


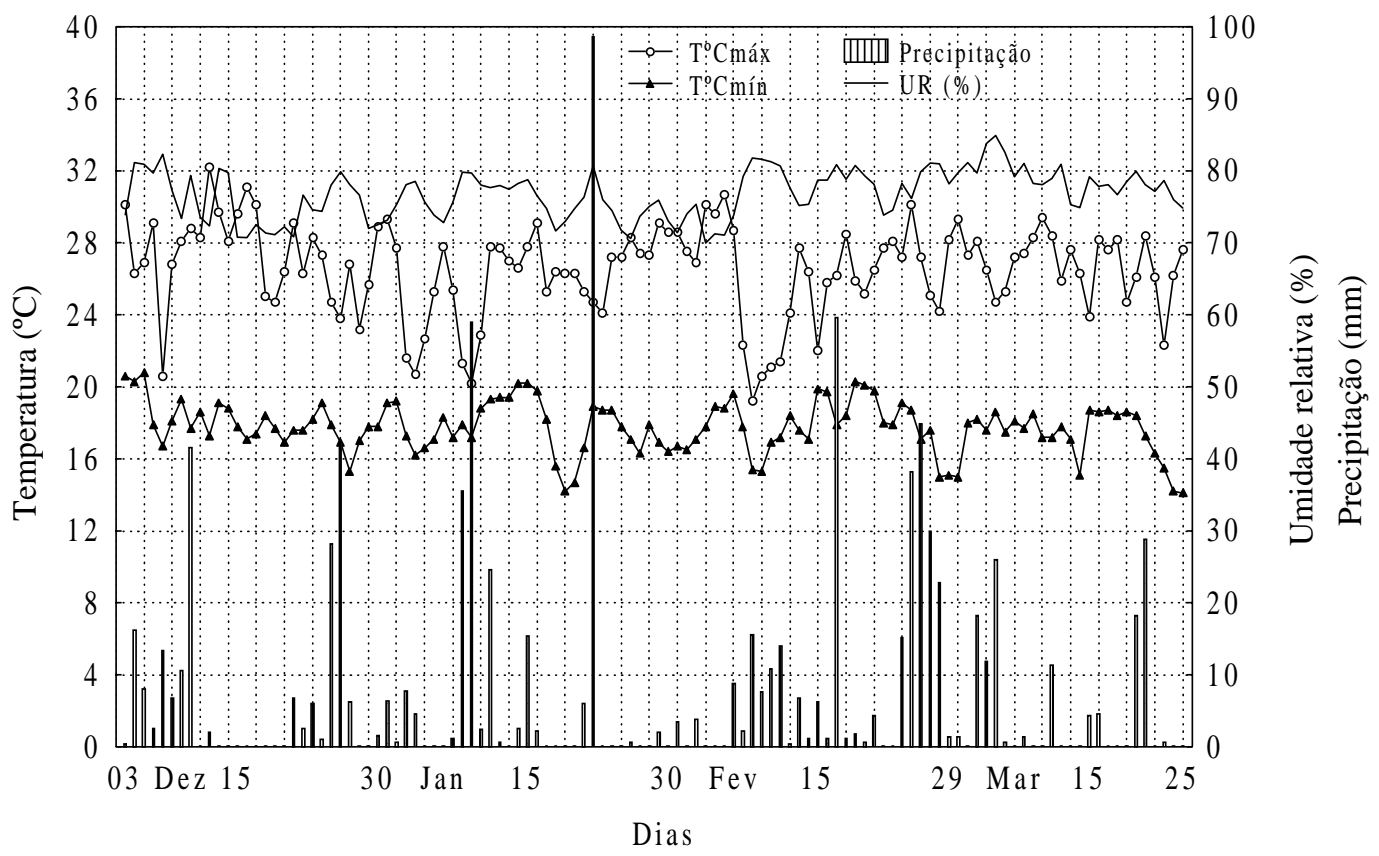

Figura 1 - Temperatura média, umidade relativa e precipitação pluvial, referentes ao período de condução do ensaio.

foi semeada entre as linhas do feijão, utilizando-se $7 \mathrm{~kg} \mathrm{ha}^{-1}$ de sementes com valor cultural de $76 \%$. A unidade experimental foi composta pela área de $21,6 \mathrm{~m}^{2}$, sendo a área útil para as avaliações de $9,6 \mathrm{~m}^{2}$. A adubação de plantio consistiu de $200 \mathrm{~kg} \mathrm{ha}^{-1}$ da formulação 8-28-16. No controle de plantas daninhas dicotiledôneas utilizou-se o herbicida fomesafen $\left(0,2 \mathrm{~kg} \mathrm{ha}^{-1}\right)$ em área total, aplicado aos 17 dias após a emergência do feijão (DAE), juntamente com $200 \mathrm{~g} \mathrm{ha}^{-1}$ de molibdato de sódio. A adubação de cobertura, realizada aos 28 dias após a emergência do feijão, consistiu de $250 \mathrm{~kg} \mathrm{ha}^{-1}$ de sulfato de amônio. Todos os demais tratos culturais e fitossanitários necessários foram realizados.

Foi utilizado um esquema de parcelas subdivididas, sendo o fator da parcela principal os cultivares de feijão (Diamante Negro e BRS Valente) consorciados com $B$. brizantha e o da subparcela as doses de fluazifop-p-butil $(0,15$, 30, 45, 60 e $75 \mathrm{~g} \mathrm{ha}^{-1}$ ), no delineamento em blocos casualizados com quatro repetições. $B$. brizantha e os cultivares de feijão foram avaliados também em monocultivo.

O fluazifop-p-butil foi aplicado aos 18 dias após a emergência do feijão - DAE, utilizandose pulverizador costal pressurizado com $\mathrm{CO}_{2}$, equipado com barra de dois bicos TT110.02, espaçados de $1,0 \mathrm{~m}$, à pressão constante de $2,5 \mathrm{kgf} \mathrm{cm}^{-2}$, aplicando-se o equivalente a $100 \mathrm{~L} \mathrm{ha}^{-1}$ de calda.

A colheita do feijão foi realizada manualmente, coletando-se todas as plantas da área útil da unidade experimental; aos 74 e 86 dias após a emergência dos cultivares Diamante Negro e BRS Valente, respectivamente, determinou-se o estande final e a produtividade de grãos da cultura. O peso de 100 sementes foi obtido de uma amostra retirada do total de sementes colhidas. Foram amostradas 15 plantas da área útil da unidade experimental, determinando-se o número de vagens por planta e o número de sementes por vagem.

A parte aérea das plantas de $B$. brizantha foi amostrada 25 dias após a colheita do cv. BRS Valente, coletando-se as plantas contidas em $1 \mathrm{~m}$ de linha da unidade experimental, sendo determinada a altura do dossel. O material vegetal coletado foi seco em estufa de circulação forçada de ar a $70{ }^{\circ} \mathrm{C} \pm 1{ }^{\circ} \mathrm{C}$, para determinação de biomassa seca.

Os dados foram submetidos à análise de variância, sendo ajustadas curvas de regressão para as características significativas referentes 
a doses de fluazifop-p-butil. Foram adotados os modelos log-logístico e logístico. O modelo log-logístico - equação 1 (Seefeldt et al., 1995) apresenta quatro parâmetros, em que $\mathbf{Y}_{\mathbf{0}}$ é o limite inferior; a é a diferença entre o limite superior e o inferior; e b descreve o declive da curva em torno de $\mathrm{I}_{50}$ (concentração do produto que inibe $50 \%$ do crescimento do bioindicador), que é dado pelo valor de $\mathbf{x}_{\mathbf{0}}$. O modelo logístico - equação 2 (Finney, 1979) possui três parâmetros: a é denominado "nível de saturação"; $\mathbf{x}_{0}$ é o ponto de inflexão da curva, que corresponde ao valor de $\mathrm{I}_{50}$; e $\mathbf{b}$ descreve o declive da curva em torno de $\mathrm{I}_{50}$.

$$
\begin{aligned}
& Y \quad Y_{0} \square \frac{a}{1 \square^{\S X^{\alpha_{0}}} \cdot{ }^{1}} \\
& Y \frac{a}{1 \square^{\S \frac{X}{a_{0}} \cdot{ }^{1}}}
\end{aligned}
$$

\section{RESULTADOS E DISCUSSÃO}

Para número de vagens por planta, de sementes por vagem, peso de 100 sementes, estande final e produtividade de grãos dos cultivares de feijão, não houve efeito de doses de fluazifop-p-butil nem da interação de doses e cultivares, indicando que a competição com $B$. brizantha não interferiu no comportamento dos cultivares.

Trabalho realizado com soja e $B$. brizantha consorciadas demonstrou que a forrageira exerceu intensa competição com a cultura, havendo necessidade da utilização de graminicida (Silva et al., 2004). Todavia, a cultura do feijão apresenta ciclo mais curto que o da soja, fechando as entrelinhas mais rapidamente, o que pode ter minimizado a competição com a forrageira. Alguns trabalhos têm demonstrado que a cultura do feijão apresenta elevada capacidade competitiva devido ao rápido acúmulo inicial de biomassa (Passini et al., 2003; Procópio et al., 2004). Outro aspecto a ser considerado é que o experimento foi instalado em solo de alta fertilidade, ocorrendo alta precipitação pluvial no período (Figura 1), o que minimizou o efeito da competição por água e nutrientes.
Na Figura 2 pode ser visualizado o efeito de cultivares de feijão. Observa-se que não houve efeito para o número de vagens por planta (A) e de sementes por vagem (B). Contudo, o cultivar BRS Valente apresentou maiores peso de 100 sementes (C), produtividade de grãos (D) e estande final $(\mathrm{E})(\mathrm{p}<0,01)$ em relação ao cultivar Diamante Negro.

O peso de 100 sementes foi o componente de produção que reduziu o rendimento de grãos do cultivar Diamante Negro, indicando que o enchimento de grãos desse cultivar foi mais comprometido pela época de plantio, resultando em decréscimo de produção. Os cultivares Diamante Negro e BRS Valente apresentaram
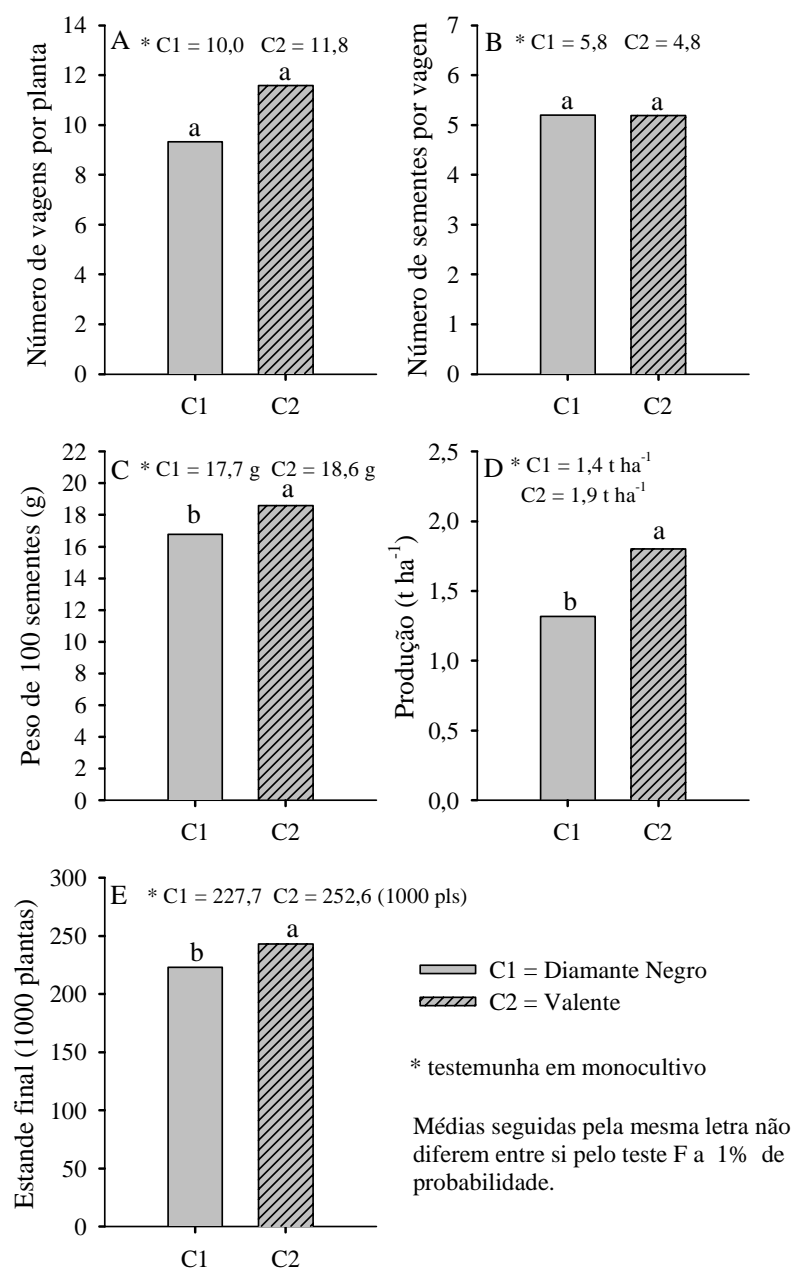

Figura 2 - Número de vagens por planta (A), de sementes por vagem (B), peso de 100 sementes (C), produtividade de grãos (D) e estande final (E) dos cultivares de feijão Diamante Negro e BRS Valente, consorciados com B. brizantha, sob subdoses de fluazifop-p-butil. 
produtividade de 1,31 e $1,80 \mathrm{t} \mathrm{ha}^{-1}$, respectivamente, ou seja, o primeiro obteve produção $27 \%$ menor que a do segundo.

O porte da planta foi um dos fatores que podem ter contribuído para o pior desempenho do cultivar Diamante Negro nessa época de plantio. Esse cultivar apresentou maior acamamento, propiciando a formação de um microclima úmido favorável à incidência de doenças, não completando o enchimento dos grãos devido à queda antecipada das folhas. O cultivar BRS Valente, de porte mais ereto e resistência ao acamamento (Peloso et al., 2003), mostrou-se mais apto ao plantio de dezembro, em condições de alta umidade.

Não houve interação de cultivares e doses nem efeito de cultivares de feijão no acúmulo de biomassa seca e na altura do dossel de $B$. brizantha, demonstrando que, embora os cultivares apresentem porte e tipo de planta distintos, essas características não interferiram de forma diferenciada no crescimento de $B$. brizantha.

O efeito de doses do fluazifop-p-butil foi significativo tanto para a biomassa seca da parte aérea $(\mathrm{p}<0,01)$ quanto para a altura do dossel $(\mathrm{p}<0,01)$ de $B$. brizantha. Na Figura 3-A pode ser visualizado o comportamento da biomassa seca de $B$. brizantha em função das doses de fluazifop-p-butil. Observa-se que na dose zero do herbicida houve acúmulo de aproximadamente $6 \mathrm{t} \mathrm{ha}^{-1}$ de biomassa seca da forrageira. Segundo Alvarenga et al. (2001), a cobertura do solo com $6 \mathrm{t} \mathrm{ha}^{-1}$ de biomassa seca é adequada ao plantio direto. Considerando que $B$. brizantha em monocultivo produziu 12,5 $\mathrm{t} \mathrm{ha}^{-1}$ de biomassa seca, fica evidente o potencial competitivo do feijoeiro, reduzindo em $50 \%$ o acúmulo de biomassa da forrageira. A dose de $15 \mathrm{~g} \mathrm{ha}^{-1}$ do fluazifopp-butil proporcionou redução de $12 \%$ de biomassa de $B$. brizantha em relação à dose zero. A dose de $15 \mathrm{~g} \mathrm{ha}^{-1}$ de fluazifop-p-butil permite ao produtor dessecar $B$. brizantha para plantio direto ou usar a forrageira como pasto, logo em seguida à colheita do feijão. Todavia, a partir de 21,2 $\mathrm{g} \mathrm{ha}^{-1}$ de fluazifop-p-butil (valor do $I_{50}$ ) há queda pronunciada de acúmulo de biomassa da forrageira atribuído ao efeito do herbicida associado ao controle cultural (sombreamento) exercido pelo feijoeiro.
A altura do dossel (Figura 3-B) de $B$. brizantha foi reduzida em todas as doses. Na dose zero houve redução de $45 \%$ em relação $a B$. brizantha em monocultivo. A partir da dose de $30 \mathrm{~g} \mathrm{ha}^{-1}$, a altura foi tomada em plantas que emergiram após a aplicação do herbicida, havendo plantas com até $40 \mathrm{~cm}$ de altura. $\mathrm{Na}$ dose de $15 \mathrm{~g} \mathrm{ha}^{-1}$, a altura de $B$. brizantha foi reduzida em 13\%, comparando-se à dose zero, o que poderia facilitar a colheita do feijão.

Os resultados permitem concluir que os cultivares de feijão BRS Valente e Diamante Negro, semeados na safra das águas, não foram afetados pelo consórcio com $B$. brizantha; o cultivar BRS Valente mostrou-se mais adeauado a essa época de plantio. O feiioeiro foi
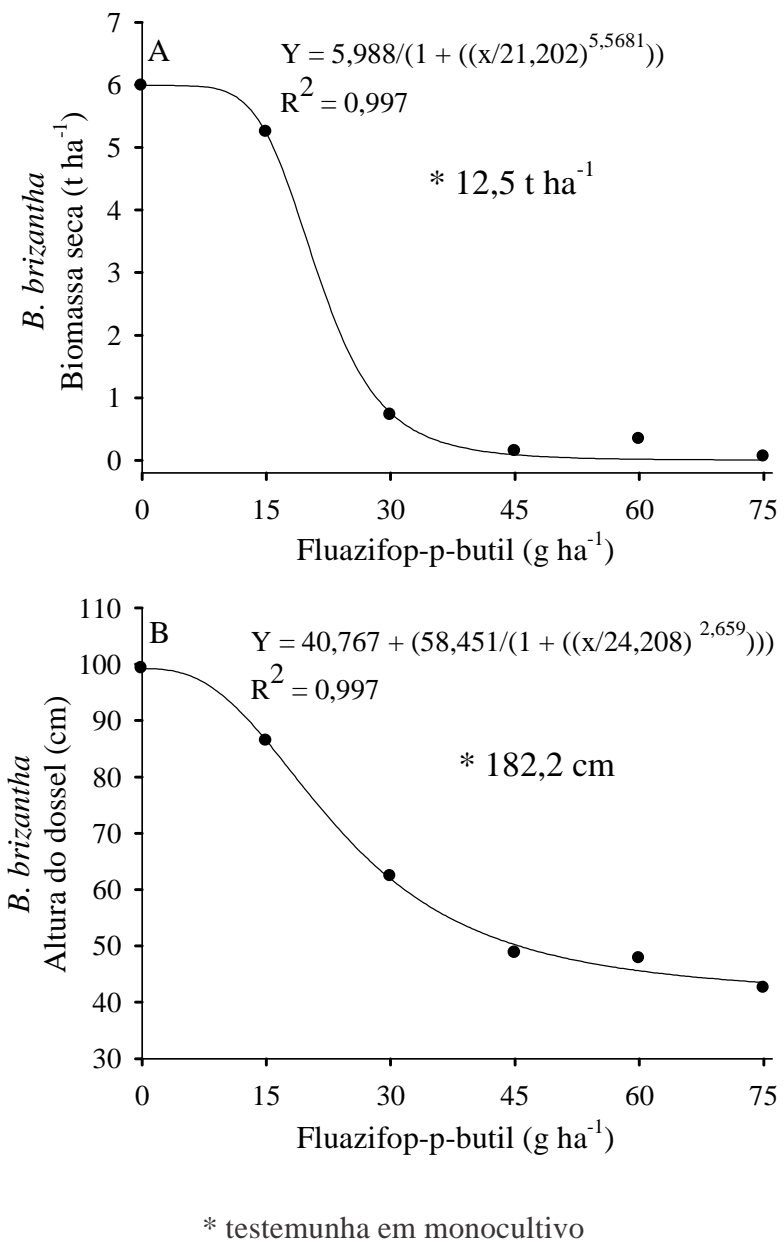

Figura 3 - Biomassa seca da parte aérea (A) e altura do dossel (B) de B. brizantha consorciada com os cultivares de feijão Diamante Negro e BRS Valente, em função de subdoses de fluazifop-p-butil..

Planta Daninha, Viçosa-MG, v. 24, n. 1, p. 71-76, 2006 
altamente competitivo com B. brizantha, ocasionando queda no acúmulo de biomassa seca da forrageira de $50 \%$ em relação a $B$. brizantha em monocultivo. A partir de $21 \mathrm{~g} \mathrm{ha}^{-1} \mathrm{de}$ fluazifop-p-butil a forrageira mostrou-se altamente sensivel ao herbicida, apresentando acúmulo de biomassa extremamente reduzido.

\section{LITERATURA CONSULTADA}

ALVARENGA, R. C. et al. Plantas de cobertura de solo para sistema plantio direto. Inf. Agropec., v. 22, n. 208, p. 25-36, 2001.

CANDAL NETO, J. F.; VIEIRA, R. F. Comportamento de cultivares de feijão (Phaseolus vulgaris L.) em consórcio com milho (Zea mays) na região serrana do Espírito Santo. R. Ceres, v. 41, n. 234, p. 168-177, 1994.

CARVALHO, H. W. L.; LEAL, M. L. S. Cultivares de milho e de feijão em monocultivo e em consórcio. II Ensaios de rendimento. Pesq. Agropec. Brás., v. 26, n. 9, p. 1467-1473, 1991.

COBUCCI, T. Manejo integrado de plantas daninhas em sistema de plantio direto. In: ZAMBOLIM, L. (Ed.). Manejo integrado fitossanidade: cultivo protegido, pivô central e plantio direto. Viçosa: Universidade Federal de Viçosa, 2001. p. 583-624.

COSTA, J. L. S.; SILVEIRA, P. M. Influência dos métodos de preparo de solo e rotação de culturas na ocorrência de podridões radiculares de feijoeiro. Fitopatol. Bras., v. 22, p. 258, 1997.

Del PELOSO, M. J. et al. 'BRS Valente' black common bean. Crop Breed. Appl. Biotechn., v. 3, n. 4, p. 311-313, 2003.

FINNEY, D. J. Bioassay and the practice of statistical inference. Int. Stat. Rev., v. 47, n. 1, p. 1-12, 1979.

GALVÃO, J. D.; RODRIGUES, J. J. V.; PURÍSSIMO, C. Sistemas de plantio direto e convencional, na cultura do feijão da seca, em Viçosa, Minas Gerais. R. Ceres, v. 28, n. 158 , p. $412-416,1981$

LOLLATO, M. A.; PARRA, M. S.; SHIOGA, P. S. Efeitos de coberturas do solo com capins marmelada e braquiária sobre o desenvolvimento do feijoeiro (Phaseolus vulgaris L.). In: CONGRESSO NACIONAL DE PESQUISA DE FEIJÃO, 7., 2002, Viçosa. Anais... Viçosa: UFV/DFT, 2002. p. 610-611.
OLIVEIRA, T. K.; CARVALHO, G. J.; MORAES, R. N. S. Plantas de cobertura e seus efeitos sobre o feijoeiro em plantio direto. Pesq. Agropec. Bras., v. 37, n. 8, p. 10791087, 2002.

PASSINI, T.; CHRISTOFFOLETI, P. J.; YADA, I. F. U. TI: Competitivity of the common bean plant relative to the weed alexandergrass [Brachiaria plantaginea (Link) Hitch.]. Sci. Agríc., v. 60, n. 2, p. 259-268, 2003.

PEREIRA FILHO, I. A.; OLIVEIRA, A. C.; CRUZ, J. C. Sistema de plantio de milho em fileiras duplas e simples em consórcio com o feijoeiro comum. Pesq. Agropec. Bras., v. 35, n. 5, p. 951-957, 2000.

PROCÓPIO, S. O. et al. Características fisiológicas das culturas de soja e feijão e de três espécies de plantas daninhas. Planta Daninha, v. 22, n. 2, p. 211-216, 2004.

SEEFELDT, S.; JENSEN, J. E.; FUERST, E. P. Log-logistic analysis of herbicide dose-response relationships. Weed Technol., v. 9, n. 2, p. 218-227, 1995.

SILVA, A.C. et al. Efeitos de doses reduzidas de fluazifop-pbutil no consórcio entre soja e Brachiaria brizantha. Planta Daninha, v. 22, n. 3, p. 429-435, 2004.

SILVA, V. A. et al. Efeitos de métodos de preparo do solo e doses de adubação NPK sobre o feijão da "seca" em seqüência à cultura do milho. Ci. Agrotec., v. 25, n. 2, p. 454-461, 2001.

STONE, L. F.; SILVEIRA, P. M. S. Efeitos do sistema de preparo na compactação do solo, disponibilidade hídrica e comportamento do feijoeiro. Pesq. Agropec. Bras., v. 34, n. 1, p. 83-91, 1999.

URCHEI, M. A.; RODRIGUES, J. D.; STONE, L. F. Análise de crescimento de duas cultivares de feijoeiro sob irrigação, em plantio direto e preparo convencional. Pesq. Agropec. Bras., v. 35, n. 3, p. 497-506, 2000.

VIEIRA, C. Cultivos consorciados. In: VIEIRA, C.; PAULA Jr., T. J.; BORÉM, A. (Eds.). Feijão - Aspectos gerais e cultura no estado de Minas. Viçosa: UFV, 1998. p. 523-558.

VIEIRA, R. F.; RAMOS, J. A. Avaliação de cultivares de feijão no consórcio com milho, em Goianira, GO. R. Ceres, v. 39, n. 225, p. 491-506, 1992.

VIEIRA, R. F.; VIEIRA, C. Comportamento de feijões dos gêneros Vigna e Phaseolus no consórcio com milho plantado simultaneamente. Pesq. Agropec. Bras., v. 31, n. 11, p. 781-787, 1996. 